\title{
Antibody-dependent cellular cytotoxicity-mediating antibodies from an HIV-1 vaccine efficacy trial preferentially use the $\mathrm{VH} 1$ gene family
}

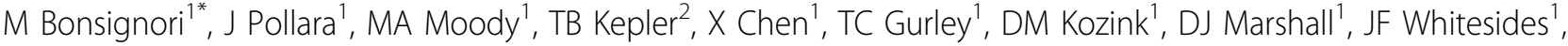

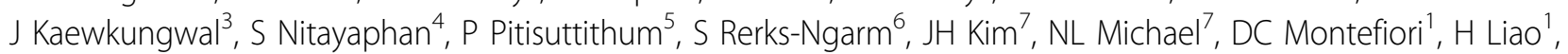 \\ G Ferrari ${ }^{1}$, BF Haynes ${ }^{1}$
}

From AIDS Vaccine 2012

Boston, MA, USA. 9-12 September 2012

\section{Background}

The ALVAC-HIV/AIDSVAX-B/E RV144 vaccine efficacy trial showed an estimated efficacy of $31 \%$. The immune correlates analysis raised the hypothesis that the observed protection in RV144 may be partially due to AntibodyDependent Cellular Cytotoxicity (ADCC)-mediating antibodies in the presence of low levels of Env IgA antibodies. In this study we analyzed the Ig VH family usage of vaccine-induced ADCC mAbs isolated from memory B cells of vaccinees.

\section{Methods}

From a total of 321,945 memory B-cells of 6 vaccinees we obtained 23 mAbs that mediated ADCC using IgG+ memory B-cell cultures $(n=9)$ and Env-specific flow cytometric single memory B-cell sorting $(\mathrm{n}=14)$. ADCC activity was measured using both E.CM243 gp120-coated and E. CM235-infected target cells in a flow-based assay.

\section{Results}

ADCC-mediating mAbs displayed a disproportionate usage of VH1 family genes $(17 / 23 ; 74 \%)$, in particular the VH1-2 gene segment (10/17; 59\%), as recently observed for CD4bs broadly neutralizing antibodies (HAAD bNAbs). In contrast, only $17.1 \%$ of 111 heavy chains isolated from cultures that did not mediate ADCC used the VH1 gene. VH1 ADCC-mediating mAbs showed a high degree of $\mathrm{V}(\mathrm{D}) \mathrm{J}$ amino acid similarity to both the $\mathrm{VH}$ (68-84\%) and VL (70-87\%) HAAD motifs. V(D)J rearrangements displayed modest levels of affinity maturation
(0.5-5.1\% for heavy chains and $0.4-4.3 \%$ for light chains). While none of the VH1 ADCC-mediating mAbs was capable of mediating HIV-1 neutralization, the strength of their ADCC activity correlated with the levels of heavy chain somatic mutations $(\mathrm{p}=0.02)$. We produced the reverted unmutated ancestor antibodies of two VH1 ADCC-mediating mAbs: one bound to B.MN Env and both reacted against autoantigens.

\section{Conclusion}

ADCC-mediating antibodies induced by the ALVAC-HIV/ AIDSVAX-B/E vaccine underwent limited affinity maturation, and preferentially used VH1 gene segments which share the HAAD motif with CD4bs bNAbs. These observations raise the hypothesis that HIV-1 Env preferentially selects VH1 family usage for distinct subsets of antibodies with different functions.

\section{Author details}

${ }^{1}$ Duke University Medical Center, Durham, NC, USA. ${ }^{2}$ Boston University School of Medicine, Boston, MA, USA. ${ }^{3}$ Tropical Hygiene, Mahidol University, Bangkok, Thailand. ${ }^{4}$ Armed Forces Research Institute of Medical Sciences, Bangkok, Thailand. ${ }^{5}$ Clinical Tropical Medicine, Mahidol University, Bangkok, Thailand. ${ }^{6}$ Department of Disease Control, Ministry of Public Health, Nonthaburi, Thailand. ${ }^{7}$ US Military HIV Research Program, Rockville, MD, USA.

Published: 13 September 2012

doi:10.1186/1742-4690-9-S2-P78

Cite this article as: Bonsignori et al:: Antibody-dependent cellular cytotoxicity-mediating antibodies from an HIV-1 vaccine efficacy trial preferentially use the VH1 gene family. Retrovirology 2012 9(Suppl 2):P78.

${ }^{1}$ Duke University Medical Center, Durham, NC, USA

Full list of author information is available at the end of the article

(c) 2012 Bonsignori et al; licensee BioMed Central Ltd. This is an Open Access article distributed under the terms of the Creative Commons Attribution License (http://creativecommons.org/licenses/by/2.0), which permits unrestricted use, distribution, and reproduction in any medium, provided the original work is properly cited. 